\title{
Inflation Targets, Credibility, and Persistence In a Simple Sticky-Price Framework
}

\author{
Jeremy Rudd \\ Karl Whelan \\ Federal Reserve Board* Central Bank of Ireland**
}

July 23, 2003

\begin{abstract}
This paper presents a re-formulated version of a canonical sticky-price model that has been extended to account for variations over time in the central bank's inflation target. We derive a closed-form solution for the model, and analyze its properties under various parameter values. The model is used to explore topics relating to the effects of disinflationary monetary policies and inflation persistence. In particular, we employ the model to illustrate and assess the critique that standard sticky-price models generate counterfactual predictions for the effects of monetary policy.
\end{abstract}

${ }^{*}$ Corresponding author. Mailing address: Mail Stop 80, 20th and C Streets NW, Washington, DC 20551. E-mail: jeremy.b.rudd@frb.gov.

**E-mail: karl.whelan@centralbank.ie. We thank Gregory Mankiw and Olivier Blanchard for useful discussions on several of the topics considered here. The views expressed in this paper are our own, and do not necessarily reflect the views of the Board of Governors, the staff of the Federal Reserve System, or the Central Bank of Ireland. 


\section{Introduction}

An important trend in macroeconomic research in recent years involves the increased use of optimization-based sticky-price models to analyze how monetary policy affects the economy and how optimal policy should be designed. Much of this analysis employs a simple baseline model that features a "new-Keynesian" Phillips curve to characterize inflation, an "expectational IS curve" to determine output growth, and a policy rule that describes how the central bank sets short-term interest rates; representative examples of studies that use this framework include Clarida, Galí, and Gertler (1999), McCallum (2001), and Woodford (2003).

One limitation of existing work in this area is that applications of the baseline model have typically been restricted to contexts in which the central bank maintains a fixed inflation target, with particular attention being paid to the effects of the type of monetary policy "shock" that is usually analyzed in the empirical VAR literature (namely, a temporary deviation from a stable policy rule). In this paper, we present a re-formulated version of the baseline sticky-price model that has been extended to account for variations over time in the central bank's inflation target. We derive a fully specified closed-form solution for the model in which output and inflation are related both to policy shocks (as usually defined) and to expected future changes in the inflation target. The model provides a simple but flexible framework for understanding a number of issues that have previously been dealt with using a range of different specifications. In particular, the model sheds light on some important existing critiques regarding the general ability of sticky-price models to capture the effects of disinflationary monetary policies.

One such critique that we consider stems from Laurence Ball's (1994) well-known example of a sticky-price economy in which an announcement of a gradual reduction in the rate of growth of the money supply results in a boom in output. This has commonly been seen as an important counterfactual prediction of these models in light of the large observed costs of disinflation; moreover, Ball's result appears at odds with the position of Woodford (2003) and others that these models adequately capture the effect of a monetary tightening on output. We use our framework to demonstrate how these apparently contradictory results can be reconciled by noting that they reflect the effects of two different types of shocks in our model. Specifically, in the more general framework that we derive here, Ball's example of a gradual disinflation that is achieved through a deceleration in the money supply is equivalent to an example where the central bank's target inflation rate is 
gradually reduced. In our framework, a credible announcement of future reductions in the inflation target will indeed result in increased output today (at least for most parameter values). However, we also demonstrate that another aspect of Ball's result-specifically, that inflation can be reduced without output's ever declining below its baseline levelrelies on a highly restrictive assumption about pricing behavior (namely, that firms do not discount their future profits).

We then use an extended version of our basic framework in order to assess the ideafirst proposed by Ball (1995) — that allowing for imperfect central bank credibility in the baseline model can restore the prediction that disinflations involve significant output losses. Specifically, we derive a general approach for modelling the effect of shocks to the inflation target when the public imperfectly perceives the target's true value, and use this setup to demonstrate that a reduction in the inflation target under these circumstances is directly analogous to a contractionary policy shock. Some of our results relating to credibility and imperfect knowledge are consistent with those found elsewhere in the literature. However, by integrating this analysis into the baseline sticky-price model - and by providing explicit closed-form solutions and a simpler, more flexible, framework for analyzing these issues - we believe our approach carries significant advantages over previous work.

An additional critique of sticky-price models that we address within our framework relates to their ability to match empirical impulse responses to monetary policy shocks. We frame our discussion around Mankiw's (2001) recent influential critique of the newKeynesian Phillips curve. Mankiw uses a variant of the new-Keynesian inflation equation to calibrate the output response that results from a gradual decline in inflation to a new, lower rate. He argues that the model's predictions (which involve a temporary increase in output) are inconsistent with VAR-based evidence on impulse responses to monetary policy shocks; this failure, he claims, provides an alternative way to view Ball's original critique of sticky-price models. As we discuss, however, Mankiw's critique misses the mark in that it fails to compare like with like: The permanent decline in inflation described in Mankiw's example must correspond to a change in the inflation target, which is different from the type of temporary policy shock that is examined in the VAR literature. Thus, this example does not imply that the baseline sticky-price model is incapable of generating a simultaneous decline in output and inflation in response to a monetary policy shock; put differently, the "Ball critique" does not extend to the shocks considered in empirical VARs.

All this said, it is still the case that the baseline sticky-price model has trouble in 
matching an important aspect of empirical impulse response functions; namely, the observed lagged response of inflation to monetary policy (and other) shocks. We therefore briefly assess the conjecture that standard sticky-price models become capable of explaining the degree of inflation persistence that is apparent in the postwar period once one allows shifts in monetary policy regimes to occur with imperfect credibility. We conclude, however, that this hypothesis provides an unconvincing explanation for the observed pattern of inflation persistence in postwar U.S. data.

\section{Variable Inflation Targets in a Sticky-Price Model}

This section derives and analyzes the closed-form solution to a sticky-price monetary business cycle model in which the central bank's inflation target can vary over time. As the model is otherwise quite standard, we briefly outline its derivation and then focus on those features of the model that are affected by the presence of a variable policy target.

\subsection{The Model}

The baseline model consists of three equations that characterize inflation, output, and interest rates. We describe each in turn.

Inflation Equation: The new-Keynesian Phillips curve that describes inflation dynamics in the baseline model can be derived from a number of different types of sticky-price models. The most commonly used formulation invokes Calvo-style pricing, in which a random fraction $(1-\theta)$ of firms reset their price each period while all other firms keep their prices unchanged. A general formulation of the problem faced by such firms involves setting the (log) time- $t$ reset price, $z_{t}$, so as to minimize

$$
L(t)=\sum_{k=0}^{\infty}(\theta \beta)^{k} E_{t}\left(z_{t}-p_{t+k}^{*}\right)^{2},
$$

where $p_{t+k}^{*}$ is the log of the optimal price that the firm would set in period $t-k$ if there were no price frictions. ${ }^{1}$ (This loss function can be motivated more generally as a secondorder Taylor approximation to the underlying profit function.) If we assume imperfect

\footnotetext{
${ }^{1}$ This formulation has been widely used in the sticky-price literature. See Devereux and Yetman (2003) and Walsh (1998) for two recent examples.
} 
competition, the frictionless optimal price will be a markup $\mu$ over nominal marginal cost; hence, the loss function becomes

$$
L(t)=\sum_{k=0}^{\infty}(\theta \beta)^{k} E_{t}\left(z_{t}-p_{t+k}-m c_{t+k}-\mu\right)^{2},
$$

where $m c_{t+k}$ is log real marginal cost at time $t+k$.

The solution to this problem takes the form

$$
z_{t}=(1-\theta \beta) \sum_{k=0}^{\infty}(\theta \beta)^{k} E_{t}\left(p_{t+k}+m c_{t+k}+\mu\right) .
$$

If we define the markup over marginal cost at time $t+k$ of a firm that last reset its price at time $t$ as

$$
\mu_{t+k, t} \equiv z_{t}-p_{t+k}-m c_{t+k}
$$

then we see that the pricing rule simply implies that firms will price to set a weighted average of expected future markups equal to the frictionless optimal markup, $\mu$ :

$$
(1-\theta \beta) \sum_{k=0}^{\infty}(\theta \beta)^{k} E_{t} \mu_{t+k, t}=\mu
$$

This pricing rule can be combined with the definition of the aggregate price level,

$$
p_{t}=\theta p_{t-1}+(1-\theta) z_{t}
$$

in order to derive an expression for inflation. ${ }^{2}$ Specifically, we obtain a new-Keynesian Phillips curve of the form:

$$
\pi_{t}=\beta E_{t} \pi_{t+1}+\frac{(1-\theta)(1-\theta \beta)}{\theta}\left(m c_{t}+\mu\right),
$$

in which inflation, $\pi_{t}$, is related to next period's expected inflation rate and the current deviation of real marginal cost from its frictionless optimal level. ${ }^{3}$

\footnotetext{
${ }^{2}$ Although the definition of the price level given by equation (6) involves taking a weighted average of log prices, it exactly corresponds to a Divisia index. Such indexes are almost identical to the Fisher chainaggregation formulae that are currently used to construct price indexes in the U.S. National Accounts (see Whelan, 2002).

${ }^{3}$ Section 1 of the Appendix provides the details of this derivation. Note that $-\mu$ is the frictionless optimal level of real marginal cost: Absent pricing frictions, the firm's optimal price $p_{t}^{*}$ is a markup $\mu$ over nominal marginal cost $m c_{t}^{n}$; hence, real marginal cost in the frictionless world, $m c_{t}^{n}-p_{t}^{*}$, equals $-\mu$, which implies that $m c_{t}-(-\mu)=m c_{t}+\mu$ is the deviation of real marginal cost from its frictionless optimal level.
} 
Finally, under the assumption that these real marginal cost deviations are proportional to the output gap $y_{t}$ (defined in turn as the deviation between actual output and its frictionless optimal level), we can write the inflation equation as:

$$
\pi_{t}=\beta E_{t} \pi_{t+1}+\gamma y_{t}
$$

Output Equation: The output gap is determined by an "intertemporal IS curve" of the form

$$
y_{t}=E_{t} y_{t+1}-\sigma\left(i_{t}-E_{t} \pi_{t+1}-r_{t}^{n}\right),
$$

in which the output gap $y_{t}$ is negatively related to the gap between the ex ante real interest rate and a potentially time-varying "natural rate" of interest. ${ }^{4}$ Note that, if the economy is to be in a steady-state equilibrium with a constant level of output and a constant inflation rate $\pi^{*}$, then it will be necessary to have

$$
i_{t}=r_{t}^{n}+\pi^{*}
$$

Monetary Policy Rule: Monetary policy is assumed to operate according to a Taylortype interest-rate feedback rule,

$$
i_{t}=r_{t}^{n}+\pi_{t}^{*}+\epsilon_{t}+\theta_{\pi}\left(\pi_{t}-\pi_{t}^{*}\right)+\theta_{y}\left(y_{t}-y_{t}^{*}\right),
$$

where $\epsilon_{t}$ represents deviations from the nominal interest rate that is required in order to keep the economy at the target rate of inflation $\left(\pi_{t}^{*}\right)$ and target level of the output gap $\left(y_{t}^{*}\right)$ in the long run. This $\epsilon_{t}$ term may also vary over time, and can therefore be equated with a monetary policy shock. ${ }^{5}$

Unlike standard implementations of the baseline model, we assume that the target inflation rate, $\pi_{t}^{*}$, can vary over time. Importantly, this also implies a varying target level of output; this is because, as Woodford (2003) and others have discussed, the newKeynesian Phillips curve implies a long-run tradeoff between the level of output and the

\footnotetext{
${ }^{4}$ The usual basis for this equation is a loglinearized consumption Euler equation. In the baseline model, consumption is equated with all output - whence equation (9) - although most authors interpret the relation as summarizing the full effect of real interest rates on aggregate expenditure.

${ }^{5}$ We assume that the interest-rate feedback rule respects the Taylor principle, which calls for the central bank to raise real rates in response to an increase in inflation. Here, this condition-which is necessary for a determinate rational-expectations equilibrium to exist-requires $\theta_{\pi}$ to be greater than $1-\frac{1-\beta}{\gamma} \theta_{y}$.
} 
level of inflation. In particular, if the central bank's target for the output gap is to be consistent with its inflation target, it must be the case that

$$
y_{t}^{*}=\frac{1-\beta}{\gamma} \pi_{t}^{*} \text {. }
$$

The existence of a positive long-run relationship between inflation and output reflects a negative long-run tradeoff between inflation and firms' average markup over marginal cost. That this average markup can vary at all from its frictionless optimal level $\mu$ in a nonstochastic steady state may appear a little surprising given that each firm's pricing rule calls for it to keep a weighted average of its expected markups equal to $\mu$ (see equation 5 ). However, as we show in section 2 of the Appendix, the fact that firms discount their future profits at a nonzero rate causes the average economy-wide markup to lie below the frictionless optimal markup in a positive-inflation steady state. In addition, this gap will widen as inflation increases - which is in turn consistent (by assumption) with a widening gap between actual output and its frictionless level.

\section{$2.2 \quad$ A Closed-Form Solution}

We can obtain the model's closed-form solution as follows. The inflation equation can be re-written as

$$
\pi_{t}-\pi_{t}^{*}=\beta E_{t}\left(\pi_{t+1}-\pi_{t+1}^{*}\right)+\gamma\left(y_{t}-y_{t}^{*}\right)+\beta E_{t} \Delta \pi_{t+1}^{*},
$$

which in turn implies that

$$
E_{t}\left(\pi_{t+1}-\pi_{t+1}^{*}\right)=\beta^{-1}\left(\pi_{t}-\pi_{t}^{*}\right)-\beta^{-1} \gamma\left(y_{t}-y_{t}^{*}\right)-E_{t} \Delta \pi_{t+1}^{*} .
$$

Substituting the Taylor rule into the IS curve and re-arranging yields the following expression for the output gap:

$$
y_{t}=E_{t} y_{t+1}-\sigma\left(\epsilon_{t}+\left(\theta_{\pi}-\beta^{-1}\right)\left(\pi_{t}-\pi_{t}^{*}\right)+\left(\theta_{y}+\beta^{-1} \gamma\right)\left(y_{t}-y_{t}^{*}\right)\right)
$$

which can be re-written as

$$
\begin{aligned}
& E_{t}\left(y_{t+1}-y_{t+1}^{*}\right) \\
& \quad=\left(1+\sigma \theta_{y}+\sigma \beta^{-1} \gamma\right)\left(y_{t}-y_{t}^{*}\right)+\sigma\left(\theta_{\pi}-\beta^{-1}\right)\left(\pi_{t}-\pi_{t}^{*}\right)+\sigma \epsilon_{t}-E_{t} \Delta y_{t+1}^{*} \\
& \quad=\left(1+\sigma \theta_{y}+\sigma \beta^{-1} \gamma\right)\left(y_{t}-y_{t}^{*}\right)+\sigma\left(\theta_{\pi}-\beta^{-1}\right)\left(\pi_{t}-\pi_{t}^{*}\right)+\sigma \epsilon_{t}-\frac{1-\beta}{\gamma} E_{t} \Delta \pi_{t+1}^{*} .
\end{aligned}
$$


These expressions imply an expectational difference equation system that can be written in matrix form as $E_{t} x_{t+1}=A x_{t}+B e_{t}$, where

$$
\begin{gathered}
A \equiv\left[\begin{array}{cc}
1+\sigma \theta_{y}+\sigma \beta^{-1} \gamma & \sigma \theta_{\pi}-\sigma \beta^{-1} \\
-\beta^{-1} \gamma & \beta^{-1}
\end{array}\right], \quad x_{t} \equiv\left[\begin{array}{c}
y_{t}-y_{t}^{*} \\
\pi_{t}-\pi_{t}^{*}
\end{array}\right], \\
B \equiv\left[\begin{array}{cc}
\sigma & -\frac{1-\beta}{\gamma} \\
0 & -1
\end{array}\right], \text { and } e_{t} \equiv\left[\begin{array}{c}
\epsilon_{t} \\
E_{t} \Delta \pi_{t+1}^{*}
\end{array}\right] .
\end{gathered}
$$

The closed-form solution of the model is therefore given by

$$
x_{t}=-A^{-1} \sum_{k=0}^{\infty} A^{-k} B E_{t} e_{t+k}
$$

which implies expressions for $y_{t}$ and $\pi_{t}$ of the form

$$
\begin{aligned}
& y_{t}=y_{t}^{*}+\sum_{k=0}^{\infty} \psi_{k}^{y} E_{t} \epsilon_{t+k}+\sum_{k=0}^{\infty} \mu_{k}^{y} E_{t} \Delta \pi_{t+k+1}^{*} \\
& \pi_{t}=\pi_{t}^{*}+\sum_{k=0}^{\infty} \psi_{k}^{\pi} E_{t} \epsilon_{t+k}+\sum_{k=0}^{\infty} \mu_{k}^{\pi} E_{t} \Delta \pi_{t+k+1}^{*} .
\end{aligned}
$$

\subsection{Properties of the Closed-Form Solution}

It is immediately apparent that the responses of inflation and the output gap to policy shocks and expected future changes in the inflation target will depend on the values of the weights $\psi_{k}^{\pi}, \psi_{k}^{y}, \mu_{k}^{\pi}$, and $\mu_{k}^{y}$, which will in turn depend on the specific values that we assume for the model's structural parameters $\beta, \sigma, \gamma, \theta_{y}$, and $\theta_{\pi}$. For example, it can be shown that the effect on $\left(y_{t}-y_{t}^{*}\right)$ of the expectation of a once-off unit increase in next period's inflation target is given by

$$
\frac{\frac{1-\beta}{\gamma}-\sigma\left(\theta_{\pi} \beta-1\right)}{1+\sigma \theta_{y}+\sigma \gamma \theta_{\pi}},
$$

which can be positive or negative. ${ }^{6}$

Figure 1 plots $\mu_{k}^{\pi}$ and $\mu_{k}^{y}$ for the two calibrations that we employ. The values of $\beta, \gamma, \theta_{y}$, and $\theta_{\pi}$ that we assume are taken from McCallum (2001), and are set such that $\beta=0.99$, $\gamma=0.03, \theta_{\pi}=1.5$, and $\theta_{y}=0.5$. For $\sigma$, which measures the elasticity of output growth with respect to changes in the real interest rate, we consider two calibrations: $\sigma=0.4$

\footnotetext{
${ }^{6}$ See section 3 of the Appendix for a derivation of this expression.
} 
(which follows McCallum) and $\sigma=1$ (which implies loglinear preferences, a commonly used benchmark). As is evident from the figure, expected future reductions in the inflation target tend to increase output (upper panel) and reduce inflation (lower panel). The intuition for these results is relatively straightforward. Because price-setters are forward looking, a lower expected future inflation target causes inflation to fall by some amount today. This lower inflation causes the central bank to ease policy, thereby raising output. ${ }^{7}$

We can also consider the values of $\psi_{k}^{y}$ and $\psi_{k}^{\pi}$, which give the effect of expected values of the "policy shock" $\epsilon$ on output and inflation; these are plotted in Figure 2. As we would expect, positive values of $\epsilon$-which correspond to increases in the central bank's policy rate (and, hence, tighter monetary policy) — tend to reduce output and inflation.

\section{The Effects of Disinflation}

We now use the model developed above to characterize the effects of disinflationary monetary policies.

\subsection{Disinflationary Booms in Our Model}

One obvious implication of the model is that a once-off permanent change in $\pi_{t}^{*}$ will immediately be fully reflected in inflation (this is apparent from equation 19). In addition, because a change in $\pi_{t}^{*}$ must also imply a change in $y_{t}^{*}$ when $\beta<1$, there will also be an immediate jump in output (c.f. equation 18). In this sense, disinflations are costly in this framework because they involve a permanent reduction in output; this reflects the fact that the long-run Phillips curve is nonvertical in this model.

Consider, however, an announcement of a gradual decline in the inflation target. To make things concrete, assume it is announced that the inflation target is being reduced by two percentage points, in equal stages, over a ten-quarter period. The response of our model economy to a policy shift of this sort is shown in Figure 3, which plots the path of output and inflation for the two parameterizations of our model. When the policy is announced, output jumps to a higher level while inflation drops - that is, a disinflationary

\footnotetext{
${ }^{7}$ The presence of a long-run tradeoff between inflation and output will mitigate this effect; specifically, a lower future inflation target implies that the central bank's target for the output gap will also be lower in the future, and this acts to reduce current output. (This latter effect can dominate if aggregate demand is sufficiently insensitive to changes in the real interest rate, which is why, when $\sigma=0.4$, we find that $\mu_{0}^{y}>0$.)
} 
boom occurs. Eventually, of course, the long-run level tradeoff between inflation and the output gap dominates, and so both variables decline over time to their new, lower levels.

As discussed above, the source of the short-term disinflationary boom is the immediate reduction in inflation that results from forward-looking price setting, which in turn allows for an immediate easing in policy. The initial decline in inflation that occurs when the policy is announced is larger than the initial decline in the inflation target because price setters correctly anticipate lower levels of output in the future. This reduction in inflation allows the central bank to loosen policy (i.e., cut interest rates) today, which has an expansionary effect on the economy. ${ }^{8}$

\subsection{Comparison with Ball's Example}

In a well-known 1994 paper, Laurence Ball constructed an example of a disinflationary boom in a sticky-price model in which output never declines below its initial level. In his example, output is assumed to be determined by a constant-velocity quantity equation (hence, output is proportional to real money balances), and monetary policy is implemented by announcing paths for the nominal money stock. It is instructive to work through this example, and to compare it with the results that we obtained in the previous subsection. ${ }^{9}$

When $y_{t}=m_{t}-p_{t}$, the new-Keynesian inflation equation becomes

$$
p_{t}-p_{t-1}=\beta E_{t} p_{t+1}-\beta p_{t}+\gamma m_{t}-\gamma p_{t}
$$

which is a second-order difference equation in the price level. This price-level equation has a solution of the form:

$$
p_{t}=\lambda_{1} p_{t-1}+\left(1-\lambda_{1}\right)\left(1-\lambda_{2}^{-1}\right) \sum_{k=0}^{\infty} \lambda_{2}^{-k} E_{t} m_{t+k}
$$

where $\lambda_{1}$ and $\lambda_{2}$ are the roots of the characteristic equation of (21).

One technical point about this equation is worth emphasizing. It may appear as though this price-level equation somehow conveys different "economic content" than the standard

\footnotetext{
${ }^{8}$ Note that a disinflationary boom does not always obtain in this model. In particular, if output is insufficiently sensitive to changes in the real interest rate, then the depressing effect of anticipated reductions in the output gap will outweigh the effect of looser monetary policy. (In this example-and with our other parameter values - this occurs if $\sigma$ is 0.1 or less.)

${ }^{9}$ We should note that in continuing to use our earlier Calvo-style representation of the pricing relationship, our formalization differs slightly from Ball's, which assumed fixed-length contracts. This difference is unimportant in this context, however.
} 
closed-form solution to the new-Keynesian Phillips curve, which can be obtained through repeated substitution:

$$
\pi_{t}=\gamma \sum_{k=0}^{\infty} \beta^{k} E_{t} y_{t+k} .
$$

For example, the price-level representation suggests that expectations about a nominal variable drive inflation rather than expectations about a real variable, and vice-versa. However, as a matter of algebra, both equations hold, and both provide valid descriptions of how inflation is determined in the model. (A complete proof of this claim is provided in section 4 of the Appendix.) In particular, it is straightforward to demonstrate that one obtains the same sequence of inflation rates either by substituting a given sequence of $m_{t}$ values into equation (22), or by substituting the implied path of real money balances (which is the path of $y_{t}$ in this model) into equation (23).

Returning to Ball's example, we assume (as he did) that monetary policy is set via direct control of the money supply. Let us also assume, as in our other model, that monetary policy has a systematic element (i.e., a potentially time-varying inflation target), and a non-systematic element $\epsilon$ :

$$
\Delta m_{t}=\pi_{t}^{*}+\epsilon_{t}
$$

The path for output can be obtained as follows:

$$
\begin{aligned}
y_{t} & =m_{t}-p_{t} \\
& =m_{t}-\lambda_{1} p_{t-1}-\left(1-\lambda_{1}\right) m_{t-1}-\left(1-\lambda_{1}\right) \sum_{k=0}^{\infty} \lambda_{2}^{-k} E_{t} \Delta m_{t+k} \\
& =\lambda_{1} y_{t-1}+\lambda_{1} \Delta m_{t}-\left(1-\lambda_{1}\right) \sum_{k=1}^{\infty} \lambda_{2}^{-k} E_{t} \Delta m_{t+k} .
\end{aligned}
$$

If we assume that $\epsilon_{t}$ follows an $A R(1)$ process with coefficient $\rho$ (and carry out a few algebraic manipulations), this becomes

$$
y_{t}=\lambda_{1} y_{t-1}+\left(\frac{1-\rho \beta}{\lambda_{1}^{-1}-\rho \beta}\right) \epsilon_{t}+\lambda_{1} \pi_{t}^{*}-\left(1-\lambda_{1}\right) \sum_{k=1}^{\infty} \lambda_{2}^{-k} E_{t} \pi_{t+k}^{*} .
$$

The coefficient on the policy shock $\epsilon_{t}$ in this expression is positive, while the coefficients on $E_{t} \pi_{t+k}^{*}$ are all negative. Hence, this equation implies that " $\epsilon$-style" positive shocks to money growth will be expansionary, but that announcements of future increases in the inflation target will be contractionary today. These results exactly parallel those presented 
in the previous section for our own model. ${ }^{10}$

One difference, though, between our results and those in Ball's paper concerns the longrun tradeoff between the levels of inflation and output. Ball described his example as one in which the gradual slowing in money growth produces a boom, where this is defined as "an output path that rises above the natural rate temporarily and never falls below the natural rate." 11 Thus, in his example there was no permanent reduction in output despite the lower level of inflation. The explanation for this difference turns out to be that Ball assumed a model in which firms do not discount profits, implying $\beta=1$. In fact, this observation helps us to reconcile what is perhaps the most puzzling aspect of Ball's result relative to the usual intuition about the new-Keynesian Phillips curve. From equation (23), we know that this relationship predicts that inflation depends positively on current and expected future output gaps. How, then, could such a model generate a path in which inflation declines even though expectations of future output gaps always lie at or above their baseline values - as in Ball's disinflationary boom example?

When $\beta$ is less than unity (as is usually assumed in structural versions of these models), the answer is that this simply cannot happen. In this case, there is a long-run tradeoff between the levels of inflation and output (equation 12), and so the initial temporary boom is eventually followed by a permanent decline in output. In our disinflationary boom example, expectations of the longer-run decline in output outweigh the effects of the temporary boom, thereby producing a decline in inflation.

In contrast, when $\beta=1$ the new-Keynesian Phillips curve becomes

$$
\pi_{t}=E_{t} \pi_{t+1}+\gamma y_{t}
$$

which implies that a zero output gap will obtain in any steady state (in which case $E_{t} \pi_{t+1}=$ $\pi_{t}$ ). Hence, a new steady-state inflation rate can be achieved without a permanent decline in output. While this notion of monetary neutrality is appealing to most macroeconomists, it is worth keeping in mind that, in this context, it can only be derived by making a somewhat unattractive assumption (namely, that firms do not discount profits).

The key technical issue underlying the difference between the case where $\beta=1$ and the

\footnotetext{
${ }^{10}$ Note, though, that the mechanism whereby expected future increases in the inflation target turn out to be contractionary is slightly different in this case. As before, these expectations result in higher inflation (and a higher price level) today. Here, however, this acts to directly reduce output by lowering real money balances, rather than indirectly through the Taylor rule.

${ }^{11}$ See Ball (1994), page 286.
} 
case where $\beta<1$ is not simply one of replacing the discount factor in equation (23) with unity. Rather, the $\beta=1$ case implies the following solution:

$$
\pi_{t}=\pi_{t}^{*}+\gamma \sum_{k=0}^{\infty} E_{t} y_{t+k},
$$

where here $\pi_{t}^{*}$ is any series that follows a martingale. ${ }^{12}$ So, in addition to having inflation depend on current and expected future output gaps, the no-discounting case permits jumps in inflation that are unrelated to the expected path of the output gap. While in theory these movements in $\pi_{t}^{*}$ could correspond to sunspot fluctuations, in practice movements in this series must be associated with changes in the inflation target if monetary policy is being carried out through the implementation of a Taylor-style interest-rate feedback rule.

\section{Credibility and Misperceptions}

The counterfactual prediction that an announced disinflationary policy can produce a temporary boom has often been cited as an important indictment of the canonical sticky-price framework. As Ball (1995) has argued, however, imperfect central bank credibility may provide a mechanism through which the model's prediction of a disinflationary boom can be overturned. In this section, we illustrate this point in the context of an extended version of our baseline sticky-price framework. Specifically, we model the credibility problem using a simple formulation in which the central bank's inflation target can be imperfectly perceived - or only partially believed — by the public.

Returning to the two equations that make up our model, recall that the inflation equation is given by

$$
\pi_{t}-\pi_{t}^{*}=\beta E_{t}\left(\pi_{t+1}-\pi_{t+1}^{*}\right)+\gamma\left(y_{t}-y_{t}^{*}\right)+\beta E_{t} \Delta \pi_{t+1}^{*}
$$

where $E_{t}$ refers to the rational expectation of private agents. However, if there were imperfect information concerning the current inflation target, this could be re-written as

$$
\pi_{t}-E_{t} \pi_{t}^{*}=\beta E_{t}\left(\pi_{t+1}-\pi_{t+1}^{*}\right)+\gamma\left(y_{t}-E_{t} y_{t}^{*}\right)+\beta E_{t} \Delta \pi_{t+1}^{*},
$$

that is, we could replace the actual values of the current inflation and output targets with the public's rational belief about them based on its available information.

\footnotetext{
${ }^{12}$ That is, any series $\pi_{t}^{*}$ for which $E_{t} \pi_{t+1}^{*}=\pi_{t}^{*}$.
} 
The output equation takes the form

$$
E_{t} y_{t+1}-y_{t}=\sigma\left(\pi_{t}^{*}+\epsilon_{t}+\theta_{\pi}\left(\pi_{t}-\pi_{t}^{*}\right)+\theta_{y}\left(y_{t}-y_{t}^{*}\right)-E_{t} \pi_{t+1}\right) .
$$

Here, however, $\pi_{t}^{*}$ and $y_{t}^{*}$ refer to the central bank's actual inflation and output targets, because these terms come from substituting the Taylor rule into the expectational IS equation. That said, we can re-write this equation as

$$
E_{t} y_{t+1}-y_{t}=\sigma\left(E_{t} \pi_{t}^{*}+\epsilon_{t}+\theta_{\pi}\left(\pi_{t}-E_{t} \pi_{t}^{*}\right)+\theta_{y}\left(y_{t}-E_{t} y_{t}^{*}\right)-E_{t} \pi_{t+1}+\eta_{t}\right)
$$

where

$$
\begin{aligned}
\eta_{t} & =\left(1-\theta_{\pi}\right)\left(\pi_{t}^{*}-E_{t} \pi_{t}^{*}\right)+\theta_{y}\left(y_{t}^{*}-E_{t} y_{t}^{*}\right) \\
& =\left(1-\theta_{\pi}-\frac{\theta_{y}(1-\beta)}{\gamma}\right)\left(\pi_{t}^{*}-E_{t} \pi_{t}^{*}\right)
\end{aligned}
$$

The model can therefore be re-formulated in terms of the deviations of the target variables from their private-sector rational expectations, with the only difference being that the monetary policy shock is now described by the composite disturbance $\epsilon_{t}+\eta_{t}$.

To illustrate what this means, note that the Taylor principle requires that the term $\left(1-\theta_{\pi}-\frac{\theta_{y}(1-\beta)}{\gamma}\right)$ be negative. Thus, if the actual inflation target is lower than the public's perception of it (implying that $\pi_{t}^{*}-E_{t} \pi_{t}^{*}<0$ ), this will act in the same way that a positive $\epsilon_{t}$ shock does. This is intuitive inasmuch as both kinds of shocks imply an unexpectedly high interest rate given the public's perception of the inflation target. However, there is an important difference between the two types of shocks that permits us to simplify the model's solution in this case. We are assuming that private agents can expect the monetary policy shock to be non-zero in the future (i.e., it is possible to have $E_{t} \epsilon_{t+k} \neq 0$ ). But if expectations are rational, private-sector agents cannot expect that their future beliefs about the inflation target will be biased. Thus, it must be that

$$
E_{t}\left[\pi_{t+k}^{*}-E_{t+k} \pi_{t+k}^{*}\right]=0
$$

Hence, the solution to this model is now of the form

$$
\begin{aligned}
y_{t}= & E_{t} y_{t}^{*}+\psi_{0}^{y}\left(1-\theta_{\pi}-\frac{\theta_{y}(1-\beta)}{\gamma}\right)\left(\pi_{t}^{*}-E_{t} \pi_{t}^{*}\right) \\
& +\sum_{k=0}^{\infty} \psi_{k}^{y} E_{t} \epsilon_{t+k}+\sum_{k=0}^{\infty} \mu_{k}^{y} E_{t} \Delta \pi_{t+k+1}^{*}
\end{aligned}
$$




$$
\begin{aligned}
\pi_{t}= & E_{t} \pi_{t}^{*}+\psi_{0}^{\pi}\left(1-\theta_{\pi}-\frac{\theta_{y}(1-\beta)}{\gamma}\right)\left(\pi_{t}^{*}-E_{t} \pi_{t}^{*}\right) \\
& +\sum_{k=0}^{\infty} \psi_{k}^{\pi} E_{t} \epsilon_{t+k}+\sum_{k=0}^{\infty} \mu_{k}^{\pi} E_{t} \Delta \pi_{t+k+1}^{*} .
\end{aligned}
$$

Besides having a relatively simple closed-form solution, this setup provides a completely general framework for thinking about the effects of policy misperceptions in the canonical sticky-price model. In particular, one can use this apparatus to construct examples of noncredible policy adjustments (or delayed learning) in which it takes the public a number of quarters to gradually adjust to a change in the central bank's inflation target. Importantly, one can also easily demonstrate that private agents' failing to fully perceive a new, lower inflation target can result in a temporary recession. In terms of the model, for most reasonable calibrations $\psi_{0}^{\pi}$ will be approximately zero while $\psi_{0}^{y}$ will be relatively large. As a result, the path of actual inflation will be effectively determined by agents' perceptions of the inflation target, $E_{t} \pi_{t}^{*}$; by contrast, deviations of $\pi_{t}^{*}$ from $E_{t} \pi_{t}^{*}$ have little effect on inflation. But for output, these misperceptions of the inflation target are like shocks to $\epsilon_{t}$, which have relatively large effects on $y_{t}$. Hence, equations (34) and (35) illustrate how the model can capture a general characteristic of imperfectly perceived disinflations - namely, an immediate decline in output coupled with a slow decline in inflation.

As a concrete example, consider the following simple experiment in which the central bank's inflation target drops by two percentage points. Assume that this is not fully perceived or believed by the public; instead, the public updates its beliefs about the target gradually by reducing its estimate of the inflation target by 0.2 percentage point each quarter for ten quarters (each time believing that this is the new, permanent target). Figure 4 gives the subsequent responses of output and inflation for the cases $\sigma=0.4$ and $\sigma=1.0$, with all other parameter values set as before. The upper panel shows that while the misperceived reduction in the inflation target produces a recession in both cases, the exact path of this contraction depends upon the sensitivity of output growth to real interest rates: In the case where $\sigma=1$, output contracts more sharply at first, overshooting its long-run level. In contrast, the path of inflation is essentially independent of $\sigma$ and closely follows the private-sector's perceived value of the inflation target, $E_{t} \pi_{t}^{*}$.

An aspect of this example that one might wish to specify more explicitly is the exact process by which the public updates its beliefs about the central bank's inflation target. One paper that takes steps in this direction is Erceg and Levin (2001). This paper presents numerical simulations of a model with sticky prices and wages in which the central bank 
has an inflation target that is the sum of two components, one being a highly persistent $A R(1)$ process and the other being white noise. In an exercise that is intended to capture the Volcker disinflation, Erceg and Levin consider the effects of a six percentage point reduction in the inflation target's persistent component under the assumption that agents can observe the target, but do not know whether its movements reflect shocks to the persistent or transitory component. In their model, agents solve a Kalman-filtering problem to gradually "learn" about the shock that has occurred. As in our example, the result is a gradual reduction in inflation and an immediate loss in output.

While a Kalman learning approach represents one way of formalizing the misperceptions problem, it is not clear that it provides a particularly suitable method for modelling the sort of credibility problem that is related to a change in a monetary policy regime. For example, in Erceg and Levin's exercise, the six percentage point jump in the permanent component of the inflation target is hard to reconcile with the underlying process that is assumed by the agents who perform the Kalman filtering: If such jumps were possible under the assumed process, then the perceived inflation target would be incredibly volatile. More generally, the idea that the inflation target can be described as the sum of a persistent (but mean-reverting) component and a transitory component is somewhat difficult to defend on common-sense grounds: A priori, a more reasonable description of reality is one in which there are infrequent discrete changes in the policy regime. Ultimately, these problems illustrate the inherent difficulty in formally modelling how agents learn about what is essentially a once-off event. However, as our own analysis has shown, the role of policy misperceptions in the sticky-price framework can be examined quite generally without reference to a specific learning model.

\section{Consistency with VAR Evidence}

In this section, we review a critique of the new-Keynesian Phillips curve that has been recently advanced by Gregory Mankiw (2001). Central to this critique is an example in which a sticky-price economy - with inflation characterized by a new-Keynesian Phillips curve - responds to a monetary policy shock with a decline in inflation and an increase in output, a response that Mankiw notes is completely at odds with the stylized facts from the VAR literature. We show that Mankiw's example is easily understood using the framework developed in this paper, and argue that his example actually pertains to the effect of a change in the inflation target, rather than to a VAR-type monetary policy shock. The 
section concludes with a discussion of whether sticky-price models are actually capable of matching the VAR evidence.

\subsection{Mankiw's Critique}

Mankiw uses a simple numerical example to criticize the realism of the new-Keynesian Phillips curve, beginning with the observation that papers from the VAR literature (such as Bernanke and Gertler, 1995) find a "delayed and gradual" response of inflation following a monetary policy shock. He then considers the following calibrated version of the newKeynesian Phillips curve:

$$
\pi_{t}=E_{t} \pi_{t+1}+\frac{1}{8} y_{t}
$$

and specifies a path for inflation based on his reading of the evidence from the VAR literature as to how inflation responds to monetary policy shocks. Given this path of inflation, a path for output is backed out using equation (36) that is consistent with both the new-Keynesian Phillips curve and the assumed inflation path.

Mankiw's calculations for inflation and output are presented in the second and third columns of Table $1 .{ }^{13}$ They show a decline in inflation to a new, permanently lower level that is accompanied by a period of positive output gaps. Mankiw argues that this example demonstrates that the logic of Ball's critique of sticky-price models carries over to impulse response functions. Specifically, he notes that: "Ball showed that in this kind of model, a fully credible announced disinflation should cause an economic boom ...[I]n essence we experience a credible announced disinflation every time we get a contractionary shock. Yet we do not get the boom that the model says should accompany it."14

What we wish to stress here is that Mankiw's example does not describe the newKeynesian Phillips curve's prediction regarding the impulse responses that obtain following the sort of monetary policy shock actually studied in the VAR literature (i.e., the $\epsilon$-style shocks of our model). Moreover, one cannot draw a simple analogy between these two types of shocks (changes in the inflation target and $\epsilon$-style policy shocks), as Mankiw does when interpreting these calculations; rather, this example only provides a further illustration of what the model predicts will occur following a permanent change in the inflation target. We have therefore labelled the column in Table 1 that gives Mankiw's inflation figures as "Path

\footnotetext{
${ }^{13}$ Mankiw's original example was actually in terms of the unemployment rate; to maintain consistency with our examples, we describe his result in terms of the output gap.

${ }^{14}$ Mankiw (2001), pages C57-C58.
} 
of inflation under target change," in order to highlight that these calculations can only represent the joint path of inflation and output under the new-Keynesian Phillips curve if they are describing a case in which the target inflation rate changes in period 1 from zero to minus two percent.

To explicitly demonstrate this point, note that Mankiw's version of the new-Keynesian Phillips curve sets the discount rate $\beta$ equal to one, so the solution for inflation is given by equation (28). This implies that the change in inflation can be described as

$$
\Delta \pi_{t}=\Delta \pi_{t}^{*}+\gamma\left[\sum_{k=0}^{\infty} E_{t} y_{t+k}-\sum_{k=-1}^{\infty} E_{t-1} y_{t+k}\right],
$$

that is, the change in inflation each period reflects changes in the inflation target and updated expectations as to the future path of the output gap.

To see that the thought experiment considered here must involve a change in the inflation target, compare columns three and four of Table 1. The fourth column (labelled "No target change") displays only the second term in equation (37); i.e., it displays the effect on inflation from the change in the expected path of the output gap. These calculations show that, absent any change in the inflation target, a shock that results in expectations of higher output produces a jump in inflation. Mankiw's calculations, by contrast, show no change in inflation during this first period, implying that the inflation target must have changed in a manner that exactly offsets the surprise positive news about output (that is, $\pi_{t}^{*}$ must have declined by two percentage points at $t=1) .{ }^{15}$ That the target must indeed have changed should also be evident from the observation that inflation settles down at -2 percent in this case even after the output gap has returned to zero. Thus, the economic intuition behind Mankiw's calculations is quite simple. The new-Keynesian Phillips curve implies that, ceteris paribus, the credible announcement of a reduction in the target inflation rate will reduce the actual inflation rate immediately. And to fit the imposed pattern of a gradual reduction in inflation, it is necessary to assume a positive sequence of output gaps. However, this example carries no implications for how well the new-Keynesian Phillips curve captures the effects of the $\epsilon$-style shocks studied in the empirical VAR literature.

In this sense, then, we would argue that Mankiw's critique of the new-Keynesian Phillips

\footnotetext{
${ }^{15}$ One other possible interpretation of Mankiw's figures is that they do not relate to an unexpected shock at all, but are rather a representation of a perfect-foresight path, i.e., one in which $\pi_{t+1}=E_{t} \pi_{t+1}$ in all periods. One can easily verify that this assumption produces the same path for output and inflation. However, it is clear from Mankiw's discussion that his example is intended to capture the effect of an unexpected shock.
} 
curve falls short of its mark. The calibrated output and inflation series in Mankiw's example do indeed fail to match the empirical impulse responses of these variables following a VARstyle shock, but because his example relates to a completely different type of shock, it is unclear as to why they are supposed to match in the first place: Our calculations in sections 2 and 3 reveal that these two types of shocks (changes in the inflation target and $\epsilon$-style policy shocks) cannot be interpreted as having similar effects on output. Moreover, by equating the two types of shocks, Mankiw's discussion suggests that the baseline stickyprice model cannot predict simultaneous declines in inflation and output in response to an $\epsilon$-type policy shock. However, our calculations in section 2 (and those presented in Woodford, 2003, and elsewhere) demonstrate that this is not the case: The announcement of a sequence of $\epsilon$-type shocks that imply a period of tighter monetary policy will result in simultaneous declines in output and inflation.

\subsection{Credibility and Persistence}

Of course, the requirement that a sticky-price model generate the correct sign of a response to an $\epsilon$-type shock serves as only a minimum objective for a model that is intended to be used for policy analysis. When one looks a little deeper, it is clear that the baseline sticky-price model still has serious difficulties in matching the empirical responses of output and inflation following a monetary policy shock. In particular, the completely forward-looking nature of output and inflation determination - which is exemplified by equations (18) and (19) results in the prediction of an overly rapid response of these variables to a shock. For example, suppose that the policy shock $\epsilon_{t}$ were characterized by an $A R(1)$ process with an autoregressive coefficient of 0.9 . Figure 5 illustrates the impulse response of inflation following a one percentage point increase in $\epsilon_{t}$; as can be seen from the figure, inflation immediately jumps (attaining its maximum response in the period that the shock hits), before gradually returning to its initial level. It is this prediction of the model - namely, the immediate and front-loaded nature of the inflation response - that is at variance with

the gradual and delayed response of inflation that is observed in VAR models following a monetary policy shock.

Ultimately, the model's failings along this dimension are connected to a well-known "persistence problem" that has been extensively discussed in the literature: The prediction that inflation should jump in response to an $\epsilon$-style policy shock appears to contradict the fact that empirical inflation regressions find a strong dependence of inflation on its own lags. 
One obvious question that arises at this point - especially in light of the results presented in the previous section - is whether allowing for misperceptions of the inflation target can help explain the observed persistence of inflation in postwar U.S. data (as well as providing a way for the sticky-price framework to capture the observed costs of disinflation). This position has been forcefully advocated by Erceg and Levin (2001), who conclude from the type of exercise discussed in the previous section - in which inflation adjusts slowly to a change in policy regime because of lack of credibility - that "... inflation persistence is not an inherent characteristic of the economy, but rather varies with the stability and transparency of the monetary policy regime." Under this view, then, inflation persistence is actually relatively low except during periods like the early 1980s, when large, permanent shifts in the inflation target were only slowly apprehended by individuals and firms.

In our opinion, this position overstates the extent to which imperfect central bank credibility serves to explain the empirical evidence on inflation persistence. Specifically, because large changes in the central bank's inflation target are probably quite infrequent, this mechanism would appear incapable of explaining inflation persistence in more than a small handful of episodes. Consider, for instance, Erceg and Levin's example of the Volcker disinflation. If one wishes to model this as a once-off change from a high-inflation regime to a low-inflation regime, then misperceptions can only explain inflation persistence during the adjustment period immediately following the regime change. ${ }^{16}$ But this cannot then explain the large degree of inflation persistence that prevailed prior to the regime change, or after the regime change was completely understood by the public. This is particularly problematic given that Stock (2001) and Pivetta and Reis (2003) document a high (and relatively stable) degree of inflation persistence both before and after the Volcker disinflation.

On balance, therefore, we do not view the imperfect credibility mechanism as providing a viable explanation for the degree of inflation persistence that is actually observed in U.S. data. Rather, we suspect that inflation persistence may more plausibly be modelled as resulting from a process in which agents use a rule of thumb based on the recent behavior of inflation in order to formulate their expectations of future inflation. While not consistent with the strict rational expectations assumption of the canonical sticky-price framework, such an approach could still be consistent with rational behavior in a world where monetary

\footnotetext{
${ }^{16}$ Worth noting, of course, is that others have viewed the regime change that occurred with Volcker's chairmanship as relating to a change in the aggressiveness with which the Fed pursued its inflation target, rather than to a change in the target itself. See Clarida, Galí, and Gertler (1999) for a discussion.
} 
policy is not perfectly credible and agents lack widespread agreement as to what constitutes a good forecasting model for inflation.

\section{Conclusions}

We have presented a version of the canonical sticky-price monetary business cycle model that has been extended to account for variations over time in the central bank's inflation target, as well as for imperfect perceptions of that target by the public. We believe that the model provides a useful unifying framework for considering a number of issues that have been discussed elsewhere using a variety of different approaches.

First, the model has been used to show that Ball's (1994) well-known disinflationary boom result (which was derived from a model in which output is determined by real money balances and monetary policy is implemented by specifying a path for the money stock) can - under most reasonable parameterizations - be carried over to the canonical stickyprice model (in which velocity can vary and policy is implemented via an interest rate rule) once one accounts for variations over time in the central bank's inflation target. However, we also show that an important feature of Ball's results - that inflation can be reduced without output's ever declining below its baseline level-hinges upon the somewhat unattractive assumption that firms do not discount future profits.

Second, we demonstrate how the idea that imperfect central bank credibility influences the costs of disinflation can be neatly integrated into the canonical sticky-price framework. That said, it seems unlikely that this mechanism can provide a realistic explanation for the framework's failure to generate the degree of inflation persistence that is found in most empirical studies.

Finally, by illustrating the differing responses of inflation and output to standard monetary policy shocks (" $\epsilon$-style" deviations of interest rates from the path consistent with a fixed inflation target) as opposed to changes in the inflation target, we believe the model provides a useful clarification of Mankiw's (2001) recent critique of the new-Keynesian Phillips curve. In particular, we reconcile Mankiw's example of declining inflation and positive output gaps following a policy tightening with more standard results in which policy shocks cause output and inflation to move in the same direction. 


\section{References}

[1] Ball, Laurence (1994). "Credible Disinflation with Staggered Price Setting," American Economic Review, 84, 282-289.

[2] Ball, Laurence (1995). "Disinflation with Imperfect Credibility," Journal of Monetary Economics, 35, 5-23.

[3] Bernanke, Ben and Mark Gertler (1995). "Inside the Black Box: The Credit Channel of Monetary Policy Transmission," Journal of Economic Perspectives, 9, 27-48.

[4] Clarida, Richard, Jordi Galí, and Mark Gertler (1999). "The Science of Monetary Policy: A New Keynesian Perspective," Journal of Economic Literature, 37, 16611707.

[5] Devereux, Michael and James Yetman (2003). "Predetermined Prices and the Persistent Effects of Money on Output" (forthcoming, Journal of Money, Credit, and Banking).

[6] Erceg, Christopher and Andrew Levin (2001). "Imperfect Credibility and Inflation Persistence," Federal Reserve Board Finance and Economics Discussion Series, 200145 (forthcoming, Journal of Monetary Economics.)

[7] Mankiw, N. Gregory (2001). "The Inexorable and Mysterious Tradeoff Between Inflation and Unemployment," Economic Journal, 111, 45-61.

[8] McCallum, Bennett (2001). "Should Monetary Policy Respond Strongly to Output Gaps?" American Economic Review, 91, 258-262.

[9] Pivetta, Frederic, and Ricardo Reis (2003). "The Persistence of Inflation in the United States," mimeo, Harvard University (March).

[10] Stock, James (2001). "Comment" on Cogley and Sargent, NBER Macroeconomics Annual 2001, 379-387.

[11] Walsh, Carl (1998). Monetary Theory and Policy, Cambridge: MIT Press.

[12] Whelan, Karl (2002). "A Guide to U.S. Chain Aggregated NIPA Data," Review of Income and Wealth, 48, 217-233.

[13] Woodford, Michael (2003). Interest and Prices, Princeton: Princeton University Press. 


\section{A Miscellaneous Results}

This Appendix provides complete demonstrations of several results that are discussed in the main text.

\section{A.1 Derivation of the New-Keynesian Phillips Curve}

Writing equation (3) in quasi-differenced form yields

$$
z_{t}=\theta \beta E_{t} z_{t+1}+(1-\theta \beta)\left(p_{t}+m c_{t}+\mu\right) .
$$

From the definition of the price level, the reset price can also be written as

$$
z_{t}=\frac{1}{1-\theta}\left(p_{t}-\theta p_{t-1}\right)
$$

Inserting this into the previous equation, we obtain

$$
\frac{1}{1-\theta}\left(p_{t}-\theta p_{t-1}\right)=\frac{\theta \beta}{1-\theta}\left(E_{t} p_{t+1}-\theta p_{t}\right)+(1-\theta \beta)\left(p_{t}+m c_{t}+\mu\right) .
$$

Multiplying across by $(1-\theta)$ leaves us with

$$
p_{t}-\theta p_{t-1}=\theta \beta E_{t} p_{t+1}-\theta^{2} \beta p_{t}+(1-\theta)(1-\theta \beta)\left(p_{t}+m c_{t}+\mu\right) .
$$

Finally, collecting terms yields a new-Keynesian Phillips curve:

$$
\pi_{t}=\beta E_{t} \pi_{t+1}+\frac{(1-\theta)(1-\theta \beta)}{\theta}\left(m c_{t}+\mu\right) .
$$

\section{A.2 Average Markups under Positive Inflation}

This section demonstrates that the average economy-wide markup will lie below the frictionless optimal markup $\mu$ in a positive-inflation steady-state so long as $\beta<1$ (i.e. firms discount future profits), and that this gap will widen as inflation increases.

In a steady-state equilibrium the cross-sectional pattern of steady-state actual markups

$\mu_{i, j}^{*}$ is fixed, with $\mu_{t+j, t}^{*}=\mu_{t, t-j}^{*}$ for all $j$. Thus, by the pricing equation (5), we have that the frictionless optimal markup $\mu$ is given by

$$
\mu=(1-\theta \beta) \sum_{j=0}^{\infty}(\theta \beta)^{j} \mu_{t+j, t}^{*}=(1-\theta \beta) \sum_{j=0}^{\infty}(\theta \beta)^{j} \mu_{t, t-j}^{*} .
$$

Similarly, the economy-wide average steady-state markup $\mu^{*}$ is given by

$$
\mu^{*}=(1-\theta) \sum_{j=0}^{\infty} \theta^{j} \mu_{t, t-j}^{*} .
$$


Our claim is that $\mu^{*} \leq \mu$ (where the inequality is strict if $\beta<1$ ), implying that

$$
\mu-\mu^{*}=(1-\theta \beta) \sum_{j=0}^{\infty}(\theta \beta)^{j} \mu_{t, t-j}^{*}-(1-\theta) \sum_{j=0}^{\infty} \theta^{j} \mu_{t, t-j}^{*} \geq 0 .
$$

This claim is proved as follows. By expanding the sums in (40) and regrouping common terms, it is straightforward to demonstrate that $\mu-\mu^{*}$ equals

$$
\sum_{j=0}^{\infty}\left[\theta^{j+1}-(\theta \beta)^{j+1}\right]\left(\mu_{t, t-j}^{*}-\mu_{t, t-j-1}^{*}\right) .
$$

Now, in a positive inflation steady-state, $\mu_{t, t-j}^{*}$ declines with $j$ : The longer a firm's price has been set, the lower is the firm's markup. Hence the terms $\left(\mu_{t, t-j}^{*}-\mu_{t, t-j-1}^{*}\right)$ will each be positive. Furthermore, when $\beta<1, \theta^{j}-(\theta \beta)^{j}$ will be positive for all $j \geq 1$. Thus, when firms discount future profits, the expression in (41) will be greater than zero in a positive-inflation steady state, which in turn implies that the average markup will lie below its frictionless optimum.

Intuitively, the reason this occurs is that discounting drives a wedge between the "population weights" that are used to compute the economy-wide average markup and the weights in the optimal pricing formula. In effect, what this does is to place a larger weight on the markups of firms who have reset prices more recently (which are higher). Moreover, as steady-state inflation rises, the cross-sectional distribution of actual markups becomes steeper, thereby driving an even wider wedge between the average markup and its frictionless optimal level (this is directly evident from equation 41 , since a higher steady-state inflation rate increases the difference between $\mu_{t, t-j}^{*}$ and $\left.\mu_{t, t-j-1}^{*}\right)$.

Hence, higher steady-state inflation causes the economy-wide average markup $\mu^{*}$ to lie even further below the optimal markup $\mu$ that obtains when pricing frictions are absent. In addition, when the average economy-wide markup lies below its frictionless level, then the average level of real marginal cost in the economy will be greater than the level of real marginal cost that prevails in the frictionless optimum-implying as well that real output will lie above its flexible-price level. This, then, is the source of the long-run level tradeoff between inflation and real activity in the model.

\section{A.3 Parameterization of the Model's Closed-Form Solution}

Recall that the closed-form solution to the model of section 2 is given by

$$
x_{t}=-A^{-1} \sum_{k=0}^{\infty} A^{-k} B E_{t} e_{t+k} .
$$


In this case, $A^{-1}$ is given by

$$
\left[\begin{array}{cc}
1+\sigma \theta_{y}+\sigma \beta^{-1} \gamma & \sigma \theta_{\pi}-\sigma \beta^{-1} \\
-\beta^{-1} \gamma & \beta^{-1}
\end{array}\right]^{-1}=\left[\begin{array}{cc}
\frac{1}{1+\sigma \theta_{y}+\sigma \gamma \theta_{\pi}} & -\sigma \frac{\theta_{\pi} \beta-1}{1+\sigma \sigma \theta_{y}+\sigma \gamma \theta_{\pi}} \\
\frac{\gamma}{1+\sigma \theta_{y}+\sigma \gamma \theta_{\pi}} & \frac{\beta+\sigma \theta_{y} \beta+\sigma \gamma}{1+\sigma \theta_{y}+\sigma \gamma \theta_{\pi}}
\end{array}\right],
$$

which in turn implies that the closed-form solution for the model is given by

$$
\left[\begin{array}{c}
y_{t}-y_{t}^{*} \\
\pi_{t}-\pi_{t}^{*}
\end{array}\right]=\sum_{k=0}^{\infty}\left[\begin{array}{cc}
\frac{1}{1+\sigma \theta_{y}+\sigma \gamma \theta_{\pi}} & -\sigma \frac{\theta_{\pi} \beta-1}{1+\sigma \theta_{y}+\sigma \gamma \theta_{\pi}} \\
\frac{\gamma}{1+\sigma \theta_{y}+\sigma \gamma \theta_{\pi}} & \frac{\beta+\sigma \theta_{y} \beta+\sigma \gamma}{1+\sigma \theta_{y}+\sigma \gamma \theta_{\pi}}
\end{array}\right]^{k+1}\left[\begin{array}{cc}
-\sigma & \frac{1-\beta}{\gamma} \\
0 & 1
\end{array}\right]\left[\begin{array}{c}
\epsilon_{t+k} \\
E_{t} \Delta \pi_{t+k+1}^{*}
\end{array}\right] .
$$

The resulting values for $\psi_{k}^{\pi}, \psi_{k}^{y}, \mu_{k}^{\pi}$, and $\mu_{k}^{y}$ in equations (18) and (19) can then be found numerically by evaluating each term of the matrix expression in the infinite sum. In particular, it is immediately evident that the effect on $\left(y_{t}-y_{t}^{*}\right)$ of a unit change in the inflation target next period equals

$$
\frac{\frac{1-\beta}{\gamma}-\sigma\left(\theta_{\pi} \beta-1\right)}{1+\sigma \theta_{y}+\sigma \gamma \theta_{\pi}}
$$

as claimed in the text.

\section{A.4 Equivalence Proof}

Here we show that the "price-level" and "inflation" solutions to the new-Keynesian Phillips curve are, in fact, completely equivalent; i.e., that equation (22) implies equation (23) as a matter of algebra.

To derive this result, first gather the terms in (21) together to obtain the following stochastic difference equation

$$
-\beta E_{t} p_{t+1}+(1+\beta+\gamma) p_{t}-p_{t-1}=\gamma m_{t}
$$

Using the lead operator $F$ and lag operator $L$, this can be re-written as

$$
\left(F^{2}-\frac{1+\beta+\gamma}{\beta} F+\frac{1}{\beta}\right) L p_{t}=-\frac{\gamma}{\beta} m_{t}
$$

This has a solution of the form

$$
\left(F-\lambda_{1}\right)\left(F-\lambda_{2}\right) L p_{t}=-\frac{\gamma}{\beta} m_{t},
$$

where $\lambda_{1}$ and $\lambda_{2}$ are the roots of the quadratic equation

$$
x^{2}-\frac{1+\beta+\gamma}{\beta} x+\frac{1}{\beta}=0 .
$$


One of these roots will be greater than one, and the other will lie between zero and one. Let $\lambda_{1}$ be the root between zero and one. Some additional manipulations give us

$$
\begin{aligned}
\left(1-\lambda_{1} L\right) p_{t} & =\frac{-\gamma}{\beta\left(F-\lambda_{2}\right)} \\
& =\frac{\gamma \beta^{-1} \lambda_{2}^{-1}}{1-\lambda_{2}^{-1} F} \\
& =\frac{\gamma}{\beta \lambda_{2}} \sum_{k=0}^{\infty} \lambda_{2}^{-k} E_{t} m_{t+k} .
\end{aligned}
$$

Now note that

$$
\lambda_{1} \lambda_{2}=\frac{1}{\beta} \Rightarrow \lambda_{2}^{-1}=\beta \lambda_{1}
$$

Hence,

$$
\begin{aligned}
\frac{1}{\beta}\left(1-\lambda_{2}^{-1}\right)\left(1-\lambda_{1}\right) & =\frac{1}{\beta}\left(1-\beta \lambda_{1}\right)\left(1-\lambda_{1}\right) \\
& =\frac{1}{\beta}\left(1-(1+\beta) \lambda_{1}+\beta \lambda_{1}^{2}\right) \\
& =\lambda_{1}^{2}-\frac{1+\beta+\gamma}{\beta} \lambda_{1}+\frac{1}{\beta}+\frac{\gamma}{\beta} \lambda_{1} \\
& =\frac{\gamma}{\beta} \lambda_{1}
\end{aligned}
$$

This allows us to re-express the term multiplying the infinite sum as $\left(1-\lambda_{2}^{-1}\right)\left(1-\lambda_{1}\right)$, since

$$
\begin{aligned}
\left(1-\lambda_{2}^{-1}\right)\left(1-\lambda_{1}\right) & =\gamma \lambda_{1} \\
& =\frac{\gamma}{\beta \lambda_{2}} .
\end{aligned}
$$

We are therefore left with the following dynamic price level equation:

$$
p_{t}=\lambda_{1} p_{t-1}+\left(1-\lambda_{1}\right)\left(1-\lambda_{2}^{-1}\right) \sum_{k=0}^{\infty} \lambda_{2}^{-k} E_{t} m_{t+k} .
$$

We can now show that the dynamic price equation implies, as a simple matter of algebra, that the inflation solution also holds. First subtract the lagged price level from both sides to obtain

$$
\pi_{t}=\left(1-\lambda_{1}\right)\left[\left(1-\lambda_{2}^{-1}\right) \sum_{k=0}^{\infty} \lambda_{2}^{-k} E_{t} m_{t+k}-p_{t-1}\right] .
$$

Subtract and add a sequence of price levels to replace each of the nominal money supplies with real money supplies (which in turn equal real output $y_{t}$ ):

$$
\pi_{t}=\left(1-\lambda_{1}\right)\left[\left(1-\lambda_{2}^{-1}\right) \sum_{k=0}^{\infty} \lambda_{2}^{-k}\left(E_{t} y_{t+k}+E_{t} p_{t+k}-p_{t-1}\right)\right] .
$$


Now re-write the future price-level terms in terms of expected future inflation

$$
\begin{aligned}
\sum_{k=0}^{\infty} \lambda_{2}^{-k}\left(E_{t} p_{t+k}-p_{t-1}\right)= & \pi_{t}+\lambda_{2}^{-1}\left(\pi_{t}+E_{t} \pi_{t+1}\right)+\lambda_{2}^{-2}\left(\pi_{t}+E_{t} \pi_{t+1}+E_{t} \pi_{t+2}\right) \\
& +\cdots \\
= & \frac{\pi_{t}+\lambda_{2}^{-1} E_{t} \pi_{t+1}+\lambda_{2}^{-2} E_{t} \pi_{t+2}+\cdots}{1-\lambda_{2}^{-1}}
\end{aligned}
$$

Again using lead operators, inflation can be written as

$$
\pi_{t}=\frac{\left(1-\lambda_{1}\right)\left(1-\lambda_{2}^{-1}\right)}{1-\lambda_{2}^{-1} F} y_{t}+\frac{1-\lambda_{1}}{1-\lambda_{2}^{-1} F} \pi_{t} .
$$

Re-arranging, we obtain

$$
\left(1-\frac{1-\lambda_{1}}{1-\lambda_{2}^{-1} F}\right) \pi_{t}=\frac{\left(1-\lambda_{1}\right)\left(1-\lambda_{2}^{-1}\right)}{1-\lambda_{2}^{-1} F} y_{t},
$$

which simplifies to

$$
\begin{aligned}
\pi_{t} & =\frac{\left(1-\lambda_{1}\right)\left(1-\lambda_{2}^{-1}\right)}{\lambda_{1}-\lambda_{2}^{-1} F} y_{t}=\frac{\gamma \lambda_{1}}{\lambda_{1}-\lambda_{2}^{-1} F} y_{t} \\
& =\frac{\gamma}{1-\lambda_{1}^{-1} \lambda_{2}^{-1} F} y_{t}=\frac{\gamma}{1-\beta F} y_{t} \\
& =\gamma \sum_{k=0}^{\infty} \beta^{k} E_{t} y_{t+k} .
\end{aligned}
$$

This is the required result. 
Table 1: Theoretical Inflation Responses to a Monetary Policy Shock

\begin{tabular}{cccc}
\hline \hline & & \multicolumn{2}{c}{ Path of inflation under } \\
\cline { 3 - 4 } Period & $y_{t}$ & $\begin{array}{c}\text { Target } \\
\text { change }\end{array}$ & $\begin{array}{c}\text { No target } \\
\text { change }\end{array}$ \\
\hline & & & \\
0 & 0.0 & 0.0 & 0.0 \\
1 & 0.8 & 0.0 & 2.0 \\
2 & 1.6 & -0.1 & 1.9 \\
3 & 2.4 & -0.3 & 1.7 \\
4 & 3.2 & -0.6 & 1.4 \\
5 & 3.2 & -1.0 & 1.0 \\
6 & 2.4 & -1.4 & 0.6 \\
7 & 1.6 & -1.7 & 0.3 \\
8 & 0.8 & -1.9 & 0.1 \\
9 & 0.0 & -2.0 & 0.0 \\
10 & 0.0 & -2.0 & 0.0 \\
$\vdots$ & & & \\
$\infty$ & 0.0 & -2.0 & 0.0 \\
& & & \\
\hline
\end{tabular}


Figure 1

Weights on Expected Future Changes in Inflation Target

A. From output equation

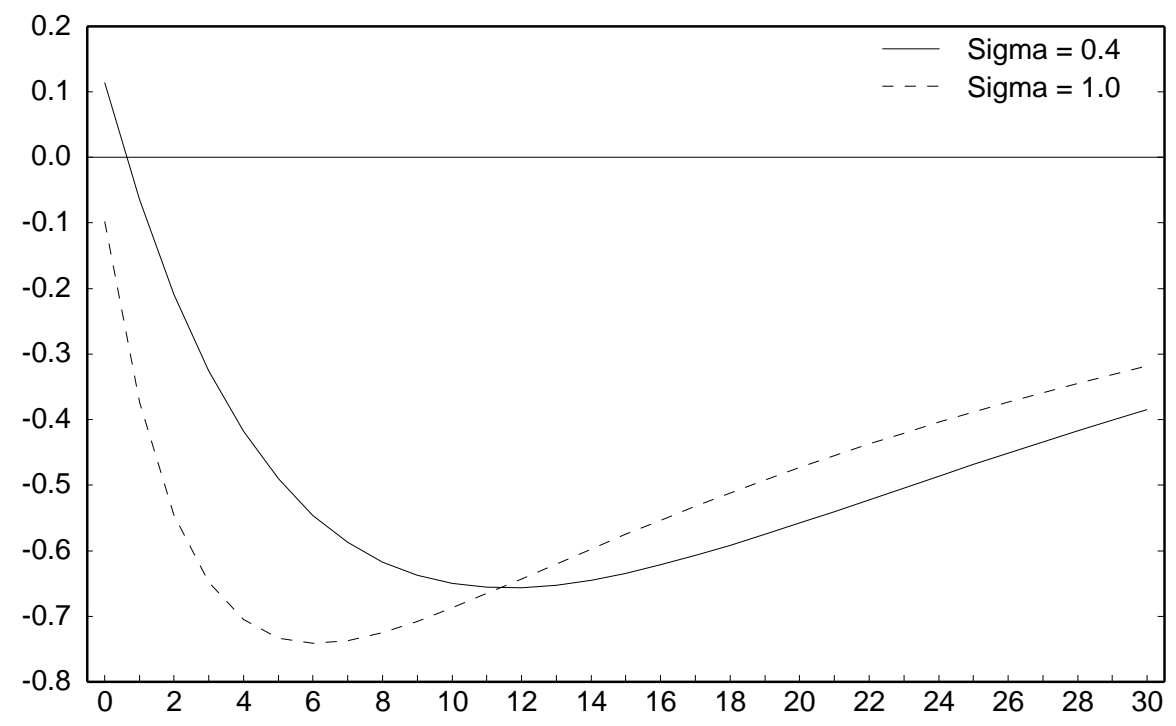

B. From inflation equation

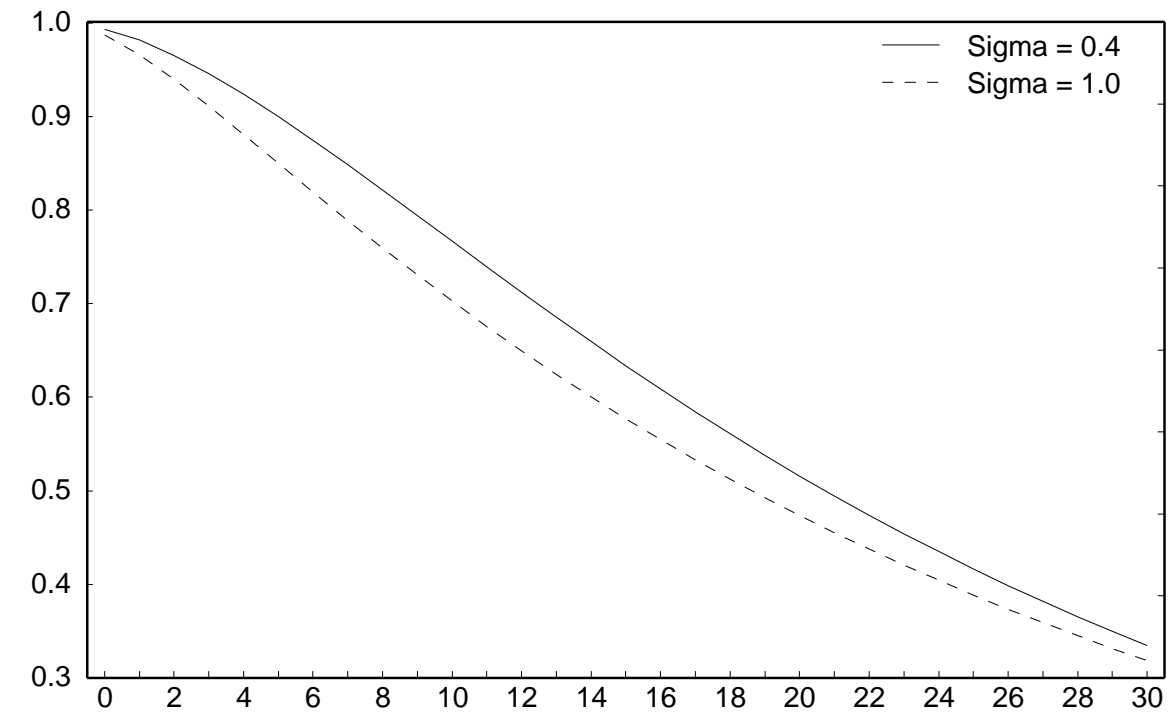


Figure 2

Weights on Expected Future Changes in Policy Shock

A. From output equation

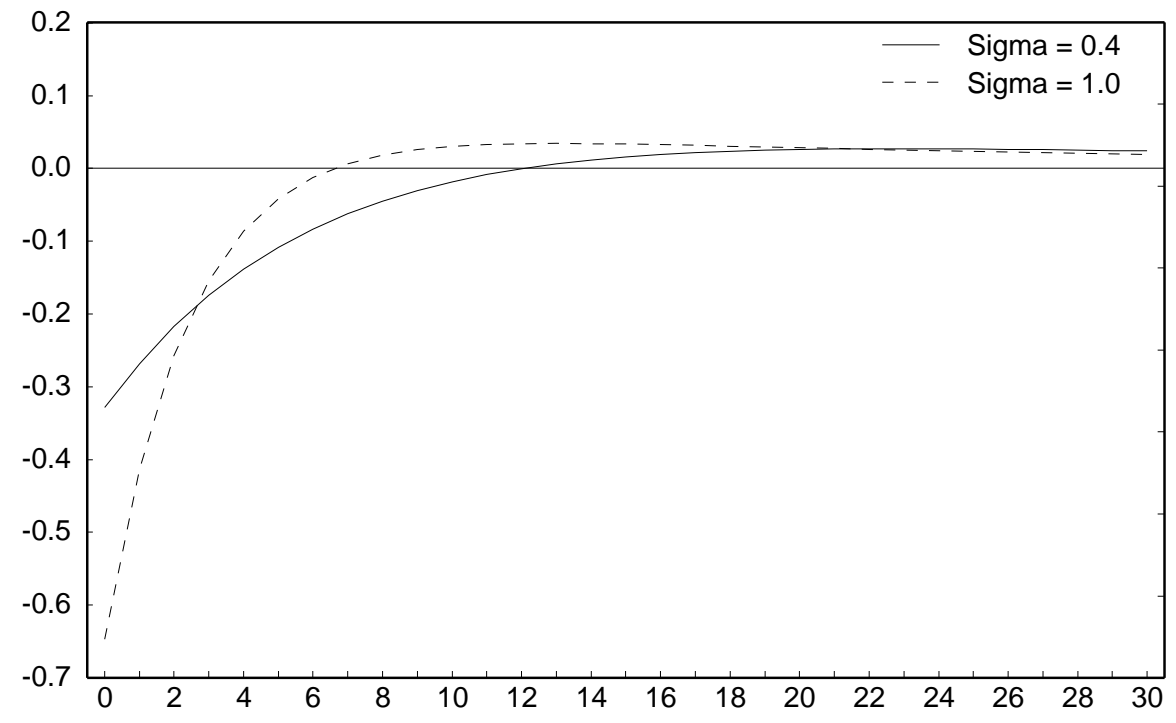

B. From inflation equation

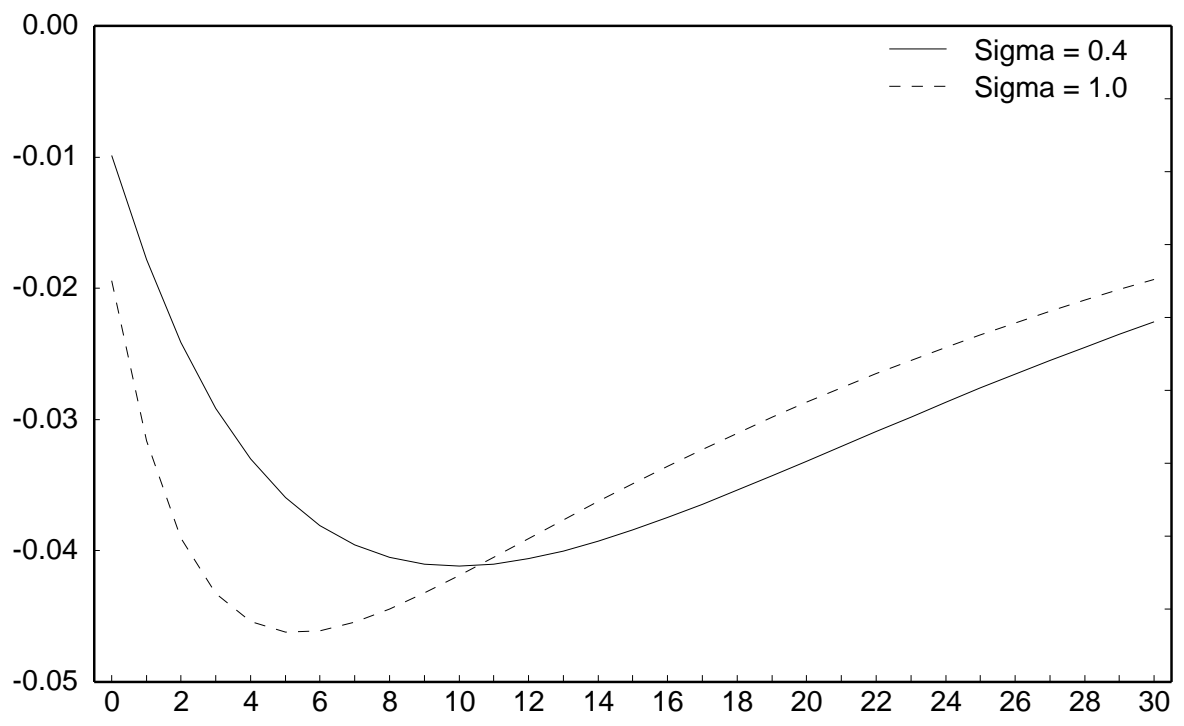


Figure 3

Impulse Responses from a Gradual Decline in the Inflation Target

A. Output response

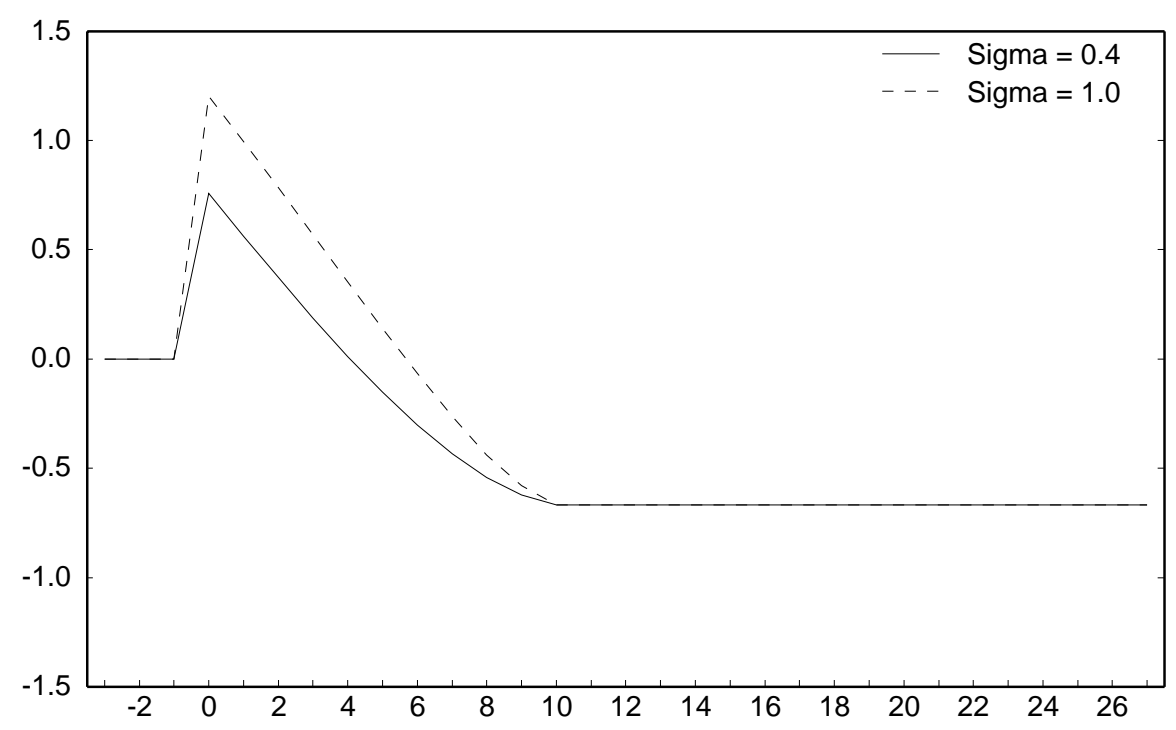

B. Inflation response

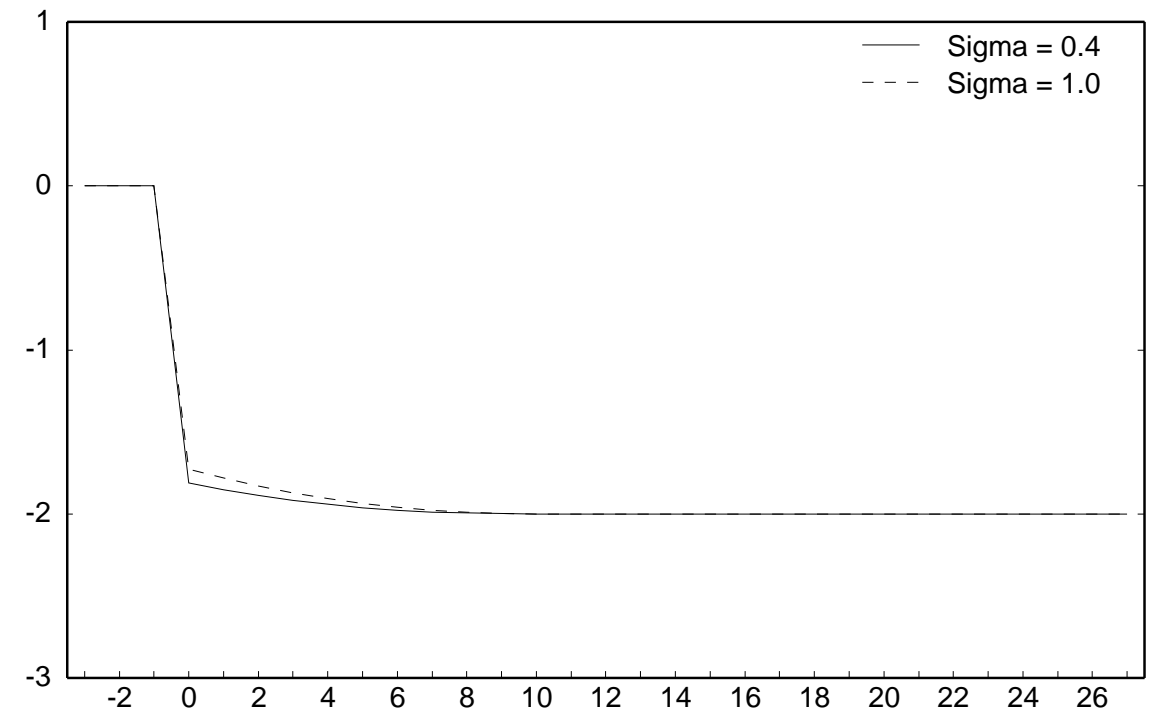


Figure 4

Impulse Responses from a Misperceived Decline in the Inflation Target

A. Output response

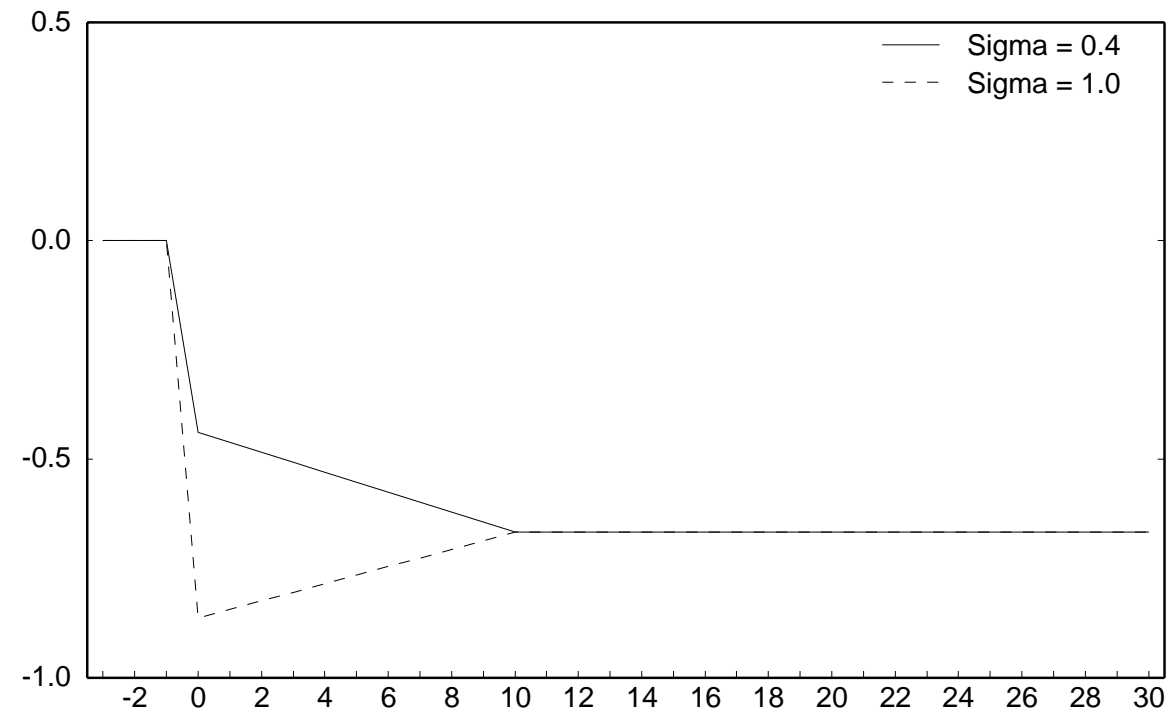

B. Inflation response

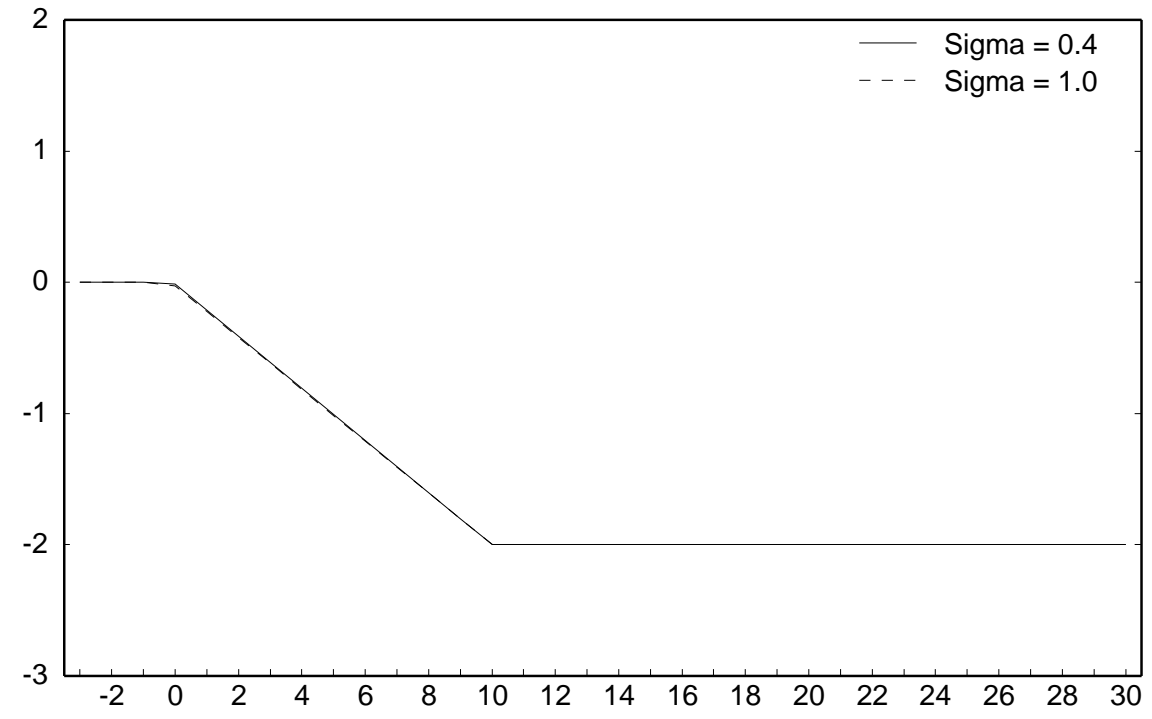


Figure 5

Response of Inflation to a Monetary Policy Shock

(Positive One Percentage Point Shock to Policy Rate)

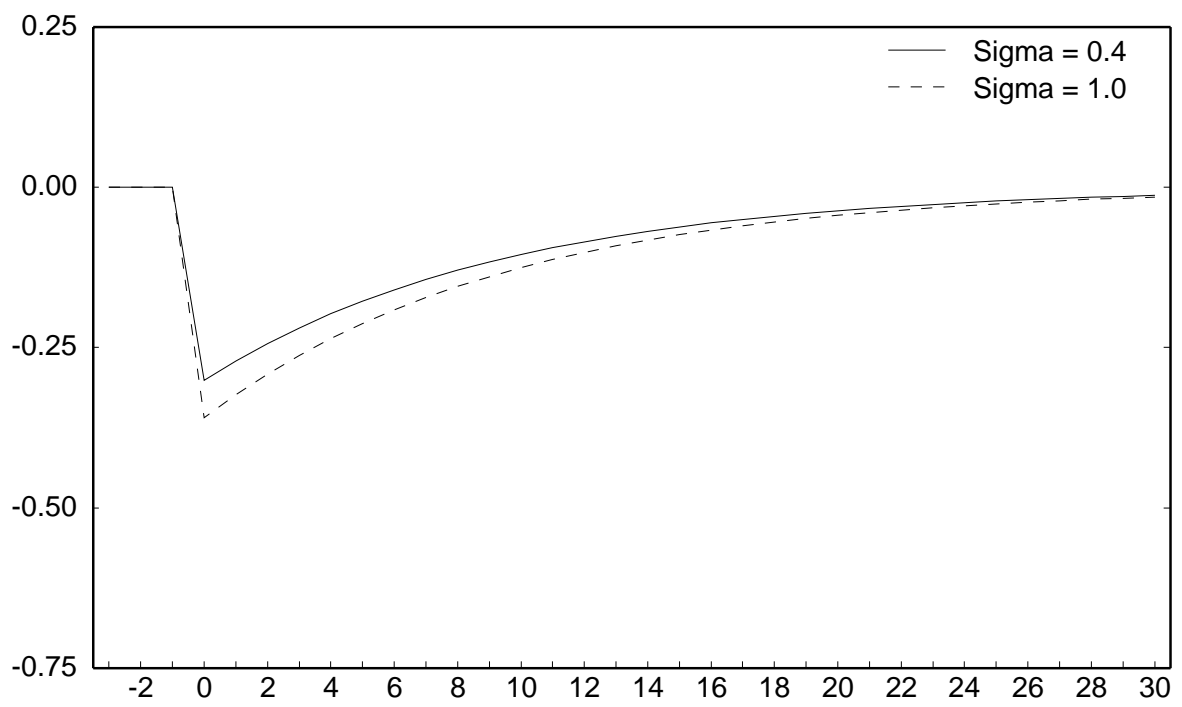

